\title{
Rousseau e a Ordem da Festa ${ }^{1}$ \\ ROUSSEAU AND THE ORDER OF THE PUBLIC CELEBRATION
}

Luc Vincenti ${ }^{2}$

\begin{abstract}
RESUMO: Longe de ser uma simples inversão de valores ou transbordamento pulsional, a festa, por sua natureza coletiva e sua relação com a política, é, antes de tudo, uma cerimônia. Porque as pessoas se entregam ao espetáculo, a festa é, para Rousseau, a oportunidade de expressar a legitimidade política profunda que se enraiza, ao lado da liberdade envolvida no contrato, na unidade da natureza humana e de toda a natureza como ordem do mundo. Assim, a ordem está presente na festa, mesmo como ordem política e social. Mas não está lá para ser respeitada em si mesma, ela não é mais do que um símbolo ou um veículo da ordem do mundo, à qual todos podem, na festa, se conectar. Portanto, existe o contentamento, e contentamento comum, em transportar-se, cada um, para o autor do seu ser, por meio de e na evidência coletiva do amor de si plenamente satisfeito.
\end{abstract}

PALAVRAS-CHAVE: Festa. Representação. Amor de si. Amor-próprio.

O título bastante pertinente deste Colóquio $^{3}$, associando festa e representação, nos remete ao cerne da abordagem rousseauniana da festa, apresentando-a imediatamente relacionada ao espetáculo e conduzindo ao problema dessa relação. Todos sabem que, quando Rousseau menciona a festa, na Carta a d'Alembert, é para opor os espetáculos, "[...] onde cada um se isola” (ROUSSEAU, 1995, p. 16), “[...] espetáculos exclusivos que, infelizmente, confinam um pequeno número de pessoas num antro obscuro" (ROUSSEAU, 1995, p. 114), e onde são colocados em fermentação os costumes de todo um povo, e as festas públicas, onde todos celebram ao ar livre a sua vontade de permanecer unidos.

O tom do discurso é duplamente moral e político: moral, no sentido de que se trata dos costumes de um povo, e também político, porque o poder comum não pode unir um povo sob leis, sem fazê-las corresponder

\footnotetext{
${ }^{1}$ Tradução de Marisa Alves Vento (doutora em Filosofia pela UNICAMP e professora de Ética e Filosofia no Instituto Federal de Educação, Ciência e Tecnologia de Goiás) - E-mail: ventomarisa@gmail.com - http://dx.doi.org/10.1590/S0101-31732015000400003

${ }^{2}$ Professor da Université Montpellier III. Associado ao C.H.S.P.M - Centre d'Histoire des Systèmes de Pensée Moderne - Université de Paris - I Sorbonne - E-mail: luc.vincenti@univ-montp3.fr

${ }^{3}$ VI Colóquio Internacional Rousseau - Pirenópolis (2013).
} 
aos costumes ${ }^{4}$. A tarefa de adaptar, assim, as leis aos costumes compete ao Legislador. Ao fazê-lo, trata-se menos de esperar corrigir, por meio de novas leis, os costumes pervertidos dos espectadores modernos (a Carta a d'Alembert exprime claramente reservas sobre este ponto $)^{5}$, mas de garantir, no exato momento da instituição ${ }^{6}$, quando o Legislador cria um novo Estado, que as vontades possam se expressar sem se subordinarem umas às outras, e os homens coexistirem, sem se submeterem uns aos outros.

Essas consideraçôes morais e políticas nos ajudam na compreensão da relação entre festa e representação. Primeiramente, a representação teatral e, depois, a representação política, quando Rousseau apresenta a festa republicana como algo que pode e deve substituir outras formas de espetáculo, pois apenas ela é capaz de dar satisfação e alegria a todos os participantes. Fora desse contexto moral e político, não se poderia compreender por que Rousseau relaciona tão estreitamente a festa ao espetáculo. Afinal, um espetáculo não é necessariamente agradável, e qualquer festa não é necessariamente o lugar de um espetáculo e nem necessariamente pública.

A festa torna-se, então, necessariamente pública na oposição problematizada por Rousseau, em sua Carta a d'Alembert, oposição entre o habitual isolamento dos teatros, de um lado, e a evidência da unidade coletiva manifestada na festa republicana, de outro. Que seja necessário haver um grande número de pessoas para "fazer a festa" não implica, sempre, reunir toda a nação, mas esse é bem o caso para opor-se ao isolamento dos teatros, que nos familiarizam com as paixóes violentas. Não se poderia fazer o mesmo em público? Sim, é claro, podemos imaginar espetáculos que reúnem um público muito numeroso. Contudo, na festa republicana, a reunião de que estamos falando não possui outro fim senão ela mesma ${ }^{7}$, o que é preciso celebrar é a unidade dos espectadores ${ }^{8}$. O político é duplamente chamado a encarnar essa

\footnotetext{
${ }^{4}$ Cf. Contrato Social, livro II, capítulo12, e Carta a d'Alembert (ROUSSEAU, 1995, p. 60 e 72).

${ }^{5}$ Cf. Carta a d'Alembert, p. 68, de preferência as p. 20-21, onde Rousseau mantém a força das leis entre os instrumentos que permitem influenciar os costumes. Eu já comentei essa alegada inutilidade moral das leis (na conferência Rousseau, Kant, et la Révolution: la force du pouvoir instituant, principalmente na parte III). Ela me parece claramente contrária ao espírito do autor, bem como várias passagens da obra. Cf. Contrato social, livro I, capítulo 8; livro II, capítulo 7; livro II, capítulo 8; Emílio, livro II, p. 311.

6 "A instituição primitiva" (Carta a d'Alembert, p. 68), o que Rousseau chama também, conforme o uso da época, de "a legislaçâa" para compreender a obra própria do grande legislador.

7 "O que isso mostra? Nada, se o quisermos" (ROUSSEAU, 1995, p. 115).

8 "[...] transformai os espectadores em espetáculo; tornai-os atores, fazei com que cada um se veja e se ame nos outros a fim de que todos estejam mais unidos” (ROUSSEAU, 1995, p. 115).
} 
unidade: primeiramente, enquanto unidade de fato - real, determinada - das sociedades políticas particulares (dada a realidade dos grupos humanos: todos vivem em um Estado hoje). E, depois, enquanto político legítimo, tipicamente rousseauniano: se todos se sentem unidos, é porque eles se encontram em pé de igualdade e, também, estâo igualmente envolvidos na composição do corpo político. Nessa igualdade prevalece não o amor-próprio que opóe, mas o amor de si, idêntico em todos e em qualquer membro da espécie.

Essa identidade é tão essencial ao político quanto constitui o fundo antropológico da vontade geral. Neste ponto, nós passamos da representação teatral, que nos distancia dos outros e de nós mesmos, para a representação política, a qual só é legítima se for fundada sobre a natureza humana comum a todos.

Nas duas primeiras partes, pretendo estabelecer a oposição de duas formas de comunidade construídas sobre essas duas bases antropológicas: o amor próprio, "[...] posto em fermentação" nos teatros, e o amor de si exaltado e plenamente satisfeito na festa pública. Sendo compreendido que a festa republicana se opóe, para Rousseau, à representação teatral, resta entender como a representação política se torna agradável.

Ao colocar a festa no centro da unidade política, podemos depreciar o sentimento de prazer que caracteriza a coesão pública; desse modo, em Consideraçóes sobre o governo da Polônia, lê-se: "[...] as festas de um povo livre devem sempre respirar a decência e a sobriedade, e devem ser apresentados para a sua admiração apenas objetos dignos de estima" (ROUSSEAU, 1966, p. 964). Há talvez uma edificação moral, mas não vemos mais onde se encontra a alegria na festa. Tentarei, na última parte, mostrar que é precisamente pela relação à natureza humana e, portanto, à espécie humana como parte do mundo, que é possível encontrar, reconhecendo que estamos em nosso lugar, o sentimento de alegria inseparável da festa.

\section{AMOR PRÓPRIO E ISOLAMENTO}

Examinarei inicialmente o isolamento característico de uma sociabilidade que desenvolve paixóes, o qual confrontarei, em seguida, com o caráter público do divertimento. Cada uma dessas duas formas de compor as sociedades humanas se opóe à outra, mas de um forma problemática, refletindo o que ela já tem em si de problemático na composição de uma 
sociedade humana. $\mathrm{O}$ amor próprio, por exemplo, opõe os indivíduos e se distingue do amor de si. Como o amor próprio permitiria constituir uma sociedade, estando os indivíduos em oposição? É fácil responder que, se o amor próprio é um sentimento que opõe os indivíduos entre si $^{9}$, suas primeiras manifestaçôes nascem na sociedade e tecem laços paradoxais que exacerbam os egoísmos. Isso vale tanto para os jovens amantes, que não podem mais deixar de se ver (ROUSSEAU, 1966, p. 169), como para as paixóes odiosas, inveja ou ciúme: "[...] quanto mais nos tornamos inimigos dos nossos semelhantes, menos nós podemos prescindir deles” (ROUSSEAU, 1966, p. 282).

Evidentemente, trata-se aqui de uma questão de representação. $\mathrm{O}$ teatro não é a vida real, porém, ao familiarizar o público com os "monstros abomináveis" e os "atos atrozes" (ROUSSEAU, 1995, p. 30), o teatro "fomenta" as paixôes dos espectadores. Rousseau realiza uma crítica radical da catharsis aristotélica: as paixões representadas não despertam senão uma piedade fraca e momentânea; no entanto, elas se instalam nos coraçóes. E se referem mais propriamente a vícios do que a virtudes. Acrescentemos que o desenvolvimento das paixóes nefastas produz no espectador o mesmo efeito que o amor próprio: colocando sua existência sob o olhar dos outros, ele opóe o ser ao parecer.

"Quanto mais reflito sobre isso, mais eu me convenço de que tudo o que é representado no teatro, não nos aproxima de nós, antes, nos afasta" (ROUSSEAU, 1995, p. 24). Desse modo, deixa de preservar o espectador. Além disso, esse afastamento das paixóes apenas lhe permite experimentar uma distância em relação ao que sente de fato, introduzindo-se uma espécie de "vida dupla" psíquica em um espectador, o qual pode, todavia, acreditar ter vivido aquilo que ele apenas sentiu. Evocando esse distanciamento interior e usando uma antífrase, Rousseau escreve, parecendo defender o espectador que é levado a admirar as belas açóes: "[...] o que mais se queria que ele fizesse? [...] Ele não é um ator” (ROUSSEAU, 1995, p. 24) Porém, poderíamos acrescentar, ao cindir assim a sua própria vida passional, separando sua vida psíquica entre o que ele vive e o que ele sente, torna-se ele próprio um ator.

Logo, o teatro é um instrumento poderoso para moldar a opinião, não só porque desperta as paixôes, mas porque estabelece no próprio espectador uma distância entre ser e parecer, a qual fortalece a opiniáo pública no sentido

9 "O amor próprio, que se compara, jamais está contente e nunca poderia estar, pois esse sentimento, preferindo-nos aos outros, exige também que os outros nos prefiram a eles, o que é impossível”. Cf. Emílio, livro IV (ROUSSEAU, 1969, p. 493). 
rousseauísta de estima pública, pois coloca a minha existência sob o olhar dos outros: "Quando não se vive em si, mas nos outros, é o julgamento deles que determina tudo" (ROUSSEAU, 1995, p. 61).

É para fugir dessa duplicidade interior que submete os indivíduos às correntes da opiniáo ${ }^{10}$, que Rousseau opóe a festa republicana à representação teatral. Entretanto, devemos entender bem a natureza dessa oposição e não estranhar o fato de que existem nas festas públicas manifestaçóes que tendem, aparentemente, ao amor próprio. Encontramos, por exemplo, oposiçóes e uma hierarquia interindividual nas festas do Governo da Polônia, onde os circos são "[...] teatros de honra e de emulação", e onde é preciso que "[...] os níveis sejam distinguidos com cuidado” (ROUSSEAU, 1966, p. 963).

Voltaremos ao sentido que se deve emprestar a essa encenação da hierarquia política. $O$ ponto importante que se deve notar é que essa hierarquia é, antes de tudo, política. Não é o caso de realçar o valor do teatro, muito ao contrário, uma vez que os espetáculos de puro entretenimento são abolidos na nova constituiçáo polonesa. Trata-se de "[...] abrilhantar as virtudes patrióticas" (ROUSSEAU, 1966, p. 962). E, para esse fim, Rousseau recomenda a utilização do instrumento poderoso da encenação. Se o Legislador está ciente da opinião pública ${ }^{11}$, não é para ceder ao livre jogo da concorrência egoísta ou para dar curso ao interesse calculado. A questão é levar o cidadáo, por meio das honrarias e premiaçóes públicas ${ }^{12}$, a amar a pátria e a transportar o amor de si que interessa, primeiramente, ao próprio indivíduo, para a nova identidade do cidadão. Portanto, se o Legislador utiliza a opiniáo, é para remeter o amor próprio contra si mesmo, dando a cada um uma identidade nova que será partilhada igualmente entre todos os compatriotas.

Desse modo, em Consideraçôes sobre o governo da Polônia, que recupera as temáticas da Carta a d'Alembert, o autor assevera que "[...] nada, se possível, de exclusivo para os grandes e os ricos. Muitos espetáculos ao ar livre, onde os lugares sejam distinguidos com cuidado, mas onde todo o povo participe igualmente" (ROUSSEAU, 1966, p. 963).

\footnotetext{
${ }^{10}$ A respeito dessas correntes, ver o "veneno da opiniáo" no Emílio, livro III, p. 444; em oposição à necessidade natural, ver Emílio, livro V, p. 856; sem esquecer a sujeição mútua na dependência dos homens, Emílio, II, p. 311.

${ }^{11}$ Cf. Contrato Social, livro II, p.12, ao final.

${ }^{12}$ Notadamente em Consideraçóes sobre o governo da Polônia, capítulo III, mas o tema está presente desde a nota XIX do Segundo Discurso.
} 


\section{AMOR DE SI E COMUNIDADE}

Sem oposição interindividual que tenha um valor em si mesmo, mas um reconhecimento ao valor dos heróis ou dos chefes, cada participante celebra a unidade do seu povo, ao mesmo tempo em que dá o testemunho individual de admiração. Assim, superadas as oposiçôes interindividuais, adentra-se numa dimensão coletiva, e o amor próprio é substituído pelo amor de si. É claro que se trata ainda de um sentimento individual, mas é um sentimento que pode ser experimentado por todos e que não opõe os indivíduos uns aos outros. Como mostram os estudos desde a primeira etapa do estado de natureza, o amor de si, primeira de todas as paixões, "[...] que nunca abandona o homem enquanto ele vive” (ROUSSEAU, 1969, p. 491), é uma paixão indiferente aos outros. O que se aprende, em contato com o outro, é que se é essencialmente idêntico a ele. É isso que justifica o apelo ao político, e a um político propriamente rousseauniano: náo apenas a instituiçáo de uma unidade coletiva, mas a constituição dessa unidade coletiva graças à participação de todos na vontade comum, a qual repousa sobre a identidade de natureza.

A temática da igualdade possui, por conseguinte, uma importância fundamental na festa republicana, ou melhor, a dimensão republicana possui uma grande importância na festa. $\mathrm{O}$ que a participação política igual póe em evidência é a profunda unidade de todos os participantes que celebram, de alguma forma, o reencontro com a sua identidade essencial enquanto se comprazem em estar juntos, e porque se comprazem em ser um todo. Não haveria manifestação de uma identidade essencial, se as oposiçóes provocadas pelo amor próprio prevalecessem.

A construção do político exige a possibilidade de um interesse comum ao qual Rousseau confere uma existência substancial, fundando esse interesse comum sobre uma identidade que não opôe os indivíduos entre si. Uma identidade antropológica essencial, baseada não só no amor de si comum a todo o ser sensível, mas também no homem, e sobre as evoluções desse amor de si impulsionado pela liberdade. Eu retornarei a essas evoluçôes, na última parte.

A unidade política construída sobre o interesse comum revela a identidade comum ou, pelo menos, redireciona a atençáo dos indivíduos para a evidência de uma natureza comum. A universalidade da natureza humana pode não estar em jogo, nas festas republicanas, pode até mesmo estar em oposição a elas, no patriotismo ou nas festas polonesas que mantêm o aspecto 
exclusivo dos "antigos legisladores"13. No entanto, está constituída a unidade, digamos intermediária, da comunidade política na qual e pela qual já estão superadas as oposições interindividuais.

Essa superação das oposiçôes interindividuais é essencial para a festa como tal, com sua dupla característica de exaltaçáo, enquanto celebração coletiva. Vemos isso em todo tipo de festa e, como apontado por J. Starobinski ${ }^{14}$, nas vindimas de Clarens: "Todos vivem na maior familiaridade, todo mundo é igual” (ROUSSEAU, 1964, p. 608). Da mesma forma, na Nona caminhada, a começar pelas oublies, essas guloseimas que Jean-Jacques distribui para as moças: "[...] a partilha se torna quase igual, e a alegria mais geral” (ROUSSEAU, 1959, p. 1091) Há, sem dúvida, a necessidade de alguma forma de igualdade obtida na partilha para se experimentar a felicidade. O tema se repete na Profissão de Fé, quando a expansão da alma nos leva à consciência de que, "[...] mesmo em nossos prazeres, seríamos muito solitários, muito miseráveis, se não tivéssemos com quem compartilhá-los"; e, na página seguinte: "[...] não queremos apenas ser felizes, nós também queremos a felicidade dos outros, e quando essa felicidade nada custa nada à nossa, ela a aumenta"15 (ROUSSEAU, 1969, p. 596-597).

No que tange à participação de cada um, essa partilha é mais uma coincidência que enriquece o prazer individual, sem que se possa atribuir esse prazer ao relacionamento interpessoal em si mesmo. Nós estamos na antípoda dos prazeres de oposição suscitados pelas paixôes do amor próprio. Assim, na zombaria mencionada na Nona caminhada, quando "[...] os ricos e os homens cultos" (ROUSSEAU, 1959, p. 1092) se divertem à custa de crianças pobres que disputam os pães doces atirados, Jean-Jacques não compartilha de sua alegria, porque ela não pode ser compartilhada por todos. A alegria individual não pode ser plena e inteira, senão numa comunidade de satisfação alheia às interações individuais. A verdadeira comunidade de celebração é, portanto, uma justaposição de contentamento, satisfaçôes individuais que se enriquecem por sua coincidência, sem serem produzidas por seu encontro ${ }^{16}$.

${ }^{13}$ Cf. Consideraçôes sobre o governo Polônia, Oeuvres Complètes, v. 3, p. 958 . É importante ver que, nessa passagem, Rousseau elogia as cerimônias religiosas nacionais e exclusivas contra as práticas sociais do seu tempo. Nada é dito aqui sobre a possibilidade de abertura da vida internacional pelo viés negativo da tolerância em relação à coexistência indiferente entre as naçóes.

14 "Na alegria geral, parece que reconquistamos a igualdade de origem" (STAROBINSKI, 1971, p. 121).

${ }^{15}$ Igualmente na p. 690: "Os prazeres exclusivos são a morte do prazer. Os verdadeiros contentamentos são aqueles que partilhamos com as pessoas."

${ }^{16}$ Cf. Luc Vincenti. J.J. Rousseau, l'individu et la Republique, capítulo 2. 
Ela é produzida, por conseguinte, pelo amor de si e não pelo amor próprio, e se manifesta, como tal, nos grupos constituídos por seu interesse comum: a família ou a cidade.

\section{DA REPRESENTAÇÁo POLÍTICA À REPRESENTAÇÁO do POLÍTICO}

Nessa igualdade essencial que permite encontrar a natureza comum, a festa manifesta ainda o que deveria ser, idealmente, o político justo: na festa, o político celebra seu ideal. A relação fundante na natureza das coisas, nesse caso, na igual liberdade da natureza humana, faz do político legítimo o contrário da desnaturação imposta pelo amor próprio e a desigualdade, os quais apenas fazem ver a desordem e o "caos"17.

O político, a hierarquia da sociedade política, representa aí a imagem da ordem do mundo, tal como ilustrado por Wolmar, em seus domínios de Clarens: "A ordem que ele estabeleceu em sua casa é a imagem daquela que prevalece nas profundezas da sua alma, e parece imitar, na pequena ordem familiar, a ordem estabelecida no governo do mundo" (ROUSSEAU, 1964, p. 371) A ordem do mundo, se ela implica igualdade entre os homens, envolve também uma hierarquia na grande cadeia dos seres ${ }^{18}$. Portanto, não é necessário apenas respeitar a igualdade natural, tratando cada indivíduo como um homem completo, mas é preciso ainda que o poder comum, ao instituir a igualdade política, faça-o manifestando a ordem do mundo que justifica a instituição.

Não basta a dimensão pública e republicana, para que a festa seja uma festa. Ela deve manifestar a igualdade essencial que faz de cada indivíduo um membro da espécie da mesma forma que o outro, o que é igualmente essencial ao político do qual ela expressa a relação com a ordem do mundo, que lhe confere legitimidade.

Não passamos, desse modo, apenas da representação teatral à representação política, entendida em um sentido democrático como a igualdade de participação de todos, nos assuntos públicos. Passamos, ao mesmo tempo, à representação do próprio político, à sua atuação nessa autocelebração

${ }^{17}$ Cf. no livro IV do Emílio: "O quadro da natureza apenas me oferecia harmonia e proporçôes, o do gênero humano somente oferece confusão e desordem! O concerto reina entre os elementos, e os homens encontram-se no caos!" (ROUSSEAU, 1969, p. 583).

${ }^{18}$ A cadeia dos seres conduz a Deus, ainda que isso não esteja numa relaçăo proporciondada às espécies inferiores. Cf. Carta ao Conde des Charmettes, 17 de janeiro de 1742. 
que é a festa republicana, demonstrando sua legitimidade, na medida em que manifesta a sua exata expressão da ordem do mundo.

Entre as principais características da festa popular, em Rousseau, quase não há inversão dos valores ou celebração do renascimento cósmico. Em contrapartida, deve-se notar a preservação de uma característica clássica da festa, que é sua expressão simbólica, não do poder ou da fertilidade, mas da harmonia natural. É quase para realçar essa característica simbólica da festa, em detrimento das outras características normalmente usadas - inversão dos valores ou celebração do renascimento cósmico -, que se aplica a Nova Heloísa: "A inversão que eles simulavam era muito superficial para instruir o mestre ou o escravo, mas a doce igualdade reinante restaura a ordem da natureza, configura uma instrução para alguns, alívio para outros, e um vínculo de amizade para todos" ${ }^{19}$ (ROUSSEAU, 1964, p. 608). Em certo sentido, o poder de expressão simbólica da festa faz dela a manifestação por excelência da instituiçẫo legítima. Ela poderia, então, como instituição de uma nova ordem, resumir em si as outras características da festa: sendo, ao mesmo tempo, inversão e renascimento.

A ordem do mundo é visível na festa como ordem e como mundo. Como mundo, principalmente, na medida em que a festa se expande ou que os participantes dão a ela um significado universal; assim, na célebre nota que conclui a Carta a d'Alembert, é preciso sublinhar que nós passamos insensivelmente da "comoçâo geral" ao "contentamento universal". Da mesma maneira, nas ceias durante a vindima na Nova Heloísa, "[...] o contentamento geral parece ser estendido sobre a superfície da Terra" (ROUSSEAU, 1964, p. 604).

A ordem do mundo é, em seguida, vista como ordem; na nota que conclui a Carta a d'Alembert, trata-se de um regimento que só se póe em marcha respeitando sua constituição, "por companhias", "segundo o costume". Quer o uníssono da dança, quer o uso dos uniformes, quer ainda o rodopiar dos dançarinos que se movimentam sem confusão, tudo denota a ordem, nessa primeira descrição da festa. A extensa banda que rodopia faz "mil voltas e círculos, mil espécies de evoluçóes figurativas”, como para demonstrar a força inovadora da natureza. A entrada em cena das mulheres parece perturbar a ordem do regimento, mas é para uni-lo a outras comunidades humanas. As mulheres constituem, principalmente, a extensão do espetáculo a essas outras comunidades. Inicialmente espectadoras, as mulheres - patroas ou

${ }^{19}$ Igualmente citado por J. Starobinski, La transparence et l'obstacle, p. 124. 
empregadas, segundo o texto, - “[...] não ficam muito tempo em suas janelas”, e descem acompanhadas das crianças. Elas se tornam atrizes e os soldados, os pais. A dança é suspensa, mas nem o texto nem a festa terminam. A chegada das mulheres, reconstituindo as famílias, é a ocasião para essa comoção geral se transformar em alegria universal.

Concluo enfatizando a simultaneidade da expansão universal da festa e da superposição das diferentes formas de comunidade: família, regimento e até mesmo a cidade, cujo contentamento testemunha a unidade de toda a Genebra. Cada uma dessas comunidades traz consigo uma identidade nova: a mulher se torna mãe, o homem, pai ou soldado, e todos são membros do corpo político. Nesse encadeamento progressivo de uma generalidade crescente, existe o esquema do que eu havia chamado ${ }^{20}$ de identidade dinâmica do indivíduo humano, dinâmica dada pela busca do bem-estar - busca da satisfação de seu amor de si - que a liberdade e a razão humana orientam para o melhor ${ }^{21}$. Percorrer as etapas dessa dinâmica, levando-nos do ser para o bem-estar, é o que explica o contentamento na festa e justifica o lugar do político como etapa que permite encontrar uma natureza comum, para além de sua individualidade primeira. É, portanto, muito importante compreender as diferentes modalidades da existência humana a partir do amor de si, essa paixão primitiva, sujeita, mais que qualquer outra, a transformaçóes cuja última é a consciência ou amor a Deus ${ }^{22}$. A festa manifesta a própria dinâmica dessa satisfação do amor de si, a qual transporta cada um de seu ser para o bem-estar comum. E, quando Jean-Jacques realiza esse percurso em seus êxtases solitários, ele não contradiz o contentamento comum da festa, porém, ele o transporta à sua plenitude, pairando sobre a ordem do universo.

VINCENTI, Luc. Rousseau and the order of the public celebration. Trans/Form/Ação, Marília, v. 38, p. 15-26, 2015. Edição Especial.

${ }^{20}$ Cf. capítulo 2 de J.J. Rousseau, l'individu et la République.

${ }^{21}$ Deus tendo nos dado "a consciência para amar o bem, a razão para conhecê-lo, a liberdade para escolhê-lo”. Cf. Nova Heloisa, parte VI, cap. 7, e Emílio, livro IV, p. 605.

${ }^{22}$ Cf. Carta a Christophe de Beaumont (ROUSSEAU, 1969, p. 936) e Emílio, livro IV, p. 636. 


\begin{abstract}
Far from being simply an inversion of values or pure instinctual overflow, the public celebration, by its collective nature and its relation to politics, is first and foremost a ceremony. For Rousseau, the reason that people give themselves over to the spectacle, the celebration, is that it is the opportunity for manifesting the profound political legitimacy which, aside from being rooted in the freedom involved in the contract, in rooted the unity of human nature and the whole of nature as the order of the world. This order is thus present in the celebration, even as social and political order. But the order is not there to be respected in itself; it is just a symbol or vehicle of world's order, to which everyone may relate through the celebration. There is therefore enjoyment, and collective enjoyment, in each one transporting himself to the author of his being in and by the collective evidence of his fully satisfied love of self.
\end{abstract}

KEYWORDS: Public celebration. Representation. Love of self. Self-love.

\title{
REFERÊNCIAS
}

ROUSSEAU, J.-J. Oeuvres complètes. Paris: Gallimard, 1959. v. 1.

Oeuvres complètes. Paris: Gallimard, 1964. v. 2.

Oeuvres complètes. Paris: Gallimard, 1966. v. 3.

Oeuvres complètes. Paris: Gallimard, 1969. v. 4.

Oeuvres complètes. Paris: Gallimard, 1995. v. 5.

STAROBINSKI, Jean. La transparence et l'obstacle. Paris: Gallimard, 1971.

VINCENTI, Luc. J.J. Rousseau, l'individu et la République. Paris: Kimé, 2001.

Rousseau, Kant, et la Révolution: la force du pouvoir instituant. In: COLLOQUE FRANCE-ALLEMAGNE: LES FIGURES DE L'INTELLECTUEL, ENTRE RÉVOLUTION ET RÉACTION (1780-1848), 2011, Paris. Disponível em: < http:// www.luc-vincenti.fr/conferences/rous_kant_rev.html >. Acesso em: 15 abr. 2013.

Recebido / Received: 15/04/2015

Aprovado / Approved: 24/06/2015 
VINCENTI, L. 